\title{
Investigation of heavy metal adsorption in binary system by nanocrystalline cellulose - Bentonite nanocomposite: Improvement on extended Langmuir isotherm model
}

\author{
Jindrayani Nyoo Putro a , Shella Permatasari Santoso a, Suryadi Ismadji a, b, *, Yi-Hsu Ju a, ** \\ a Department of Chemical Engineering, National Taiwan University of Science and Technology, No. 43, Sec 4, Keelung Rd, Da'an District, Taipei City, 106, \\ Taiwan \\ b Department of Chemical Engineering, Widya Mandala Surabaya Catholic University, Kalijudan 37, Surabaya, 60114, Indonesia
}

\section{A R T I C L E I N F O}

\section{Article history:}

Received 23 February 2017

Received in revised form

17 March 2017

Accepted 18 March 2017

Available online 21 March 2017

\section{Keywords:}

Bentonite

Nanocellulose

Composite

Isotherms

Adsorption

\begin{abstract}
A B S T R A C T
The preparation of NCC - bentonite nanocomposite using waste paper as the source of NCC was conducted in this study. The adsorption performance of the composite was tested for the removal of $\mathrm{Pb}(\mathrm{II})$ and $\mathrm{Hg}(\mathrm{II})$ from aqueous solution in single and binary systems. Langmuir and Freundlich adsorption isotherms were employed to correlate pure component adsorption isotherm. Langmuir equation can represent the experimental data better than Freundlich, the $q_{m}$ for lead is higher than mercury in both systems (single system $q_{m}=0.44 \mathrm{mmol} / \mathrm{g}(\mathrm{Pb})$ and $0.23 \mathrm{mmol} / \mathrm{g}(\mathrm{Hg})$ for composite). All systems exhibit endothermic process, except for bentonite which shows the exothermic process. The modification of extended Langmuir model for a binary system with the inclusion of fractional loading and heat of adsorption was proposed in this study. The modified extended Langmuir model could represent the experimental data better than original extended Langmuir equation.
\end{abstract}

๑) 2017 Elsevier Inc. All rights reserved.

\section{Introduction}

The rapid grow of industrialization in the 21st century makes the human life much easier. On the other hand, these rapid developments ruin the environment with many kinds of industrial hazardous wastes. One of the biggest problems that the human encountered today is clean water shortage and severe water pollution. Contamination of water resources with various kind of industrial hazardous substances becomes one of the biggest problems for underdeveloped and some of developing countries.

Heavy metals are some of the most harmful contaminants which usually were found in the polluted water environments. Heavy metals in contaminated water such as lead and mercury can highly damage human health and other living organisms. Prolonged exposure to these metals can cause blood and brain

\footnotetext{
* Corresponding author. Department of Chemical Engineering, Widya Mandala Surabaya Catholic University, Kalijudan 37, Surabaya, 60114, Indonesia.

** Corresponding author. Department of Chemical Engineering, National Taiwan University of Science and Technology, No. 43, Sec 4, Keelung Rd, Da'an District, Taipei City, 106, Taiwan.

E-mail addresses: suryadiismadji@yahoo.com (S. Ismadji), yhju@mail.ntust.edu. tw (Y.-H. Ju).
}

disorders. Reducing or eliminating the heavy metals content of wastewater before discharging to the water environment is a way to handle this major environment problem. Adsorption is one of the various techniques which is widely used for removing contaminants in water. This process is a very efficient and economical method which results in high-quality water decontamination [1].

Recently, natural polymer adsorbents have been given tremendous attention as biosorbents due to their ubiquitous, biodegradability, and non-toxic nature. One of the natural polymers that has potential application as biosorbent is cellulose. Cellulose is considered as the most abundant natural material in the world, which is composed of linear polysaccharides consisted of two anhydroglucose rings linked by repeated $\beta-1,4$ glycoside bonds [2]. Cellulose is an important raw material for many kinds of industries, especially for pulp and paper industries. In 2014, the total graphic papers (newsprint, uncoated mechanical, uncoated woodfree, and coated papers) consumption was $56 \mathrm{Mt}$ for Europe and Northern America region; then it can be assumed that the waste paper has the same amount of the total consumption number [3]. Waste papers usually are used as feedstocks for making recycled paper. However, after several times of recycling, cellulose fibers become short and has lower economic value than long cellulose fibers. To increase the added value of waste paper, the possibility of utilizing 
waste paper as raw material for nanocrystalline cellulose (NCC) production was explored in this study.

Cellulose has hydroxyl functional groups that can be modified to enhance its adsorption ability as an adsorbent. Currently, several methods are available for the modification of cellulose such as esterification, etherification, cationization, oxidation, amidation, and grafting. Among these methods, esterification through acid hydrolysis has been shown to improve cellulose properties excellently. Acid hydrolysis is a simple method to modify cellulose. Basically the acid will attack the amorphous part in cellulose fiber and extract the nanocrystalline cellulose (NCC). Sulfuric acid prepared NCC is well known for excellent thermal stability property due to the attachment of sulfate esters on the NCC surface. The presence of sulfate ester in the NCC surface increases the adsorption capacity two times of that of the original NCC, which means that modification of functional groups indeed has a major impact on adsorption capacity [4].

Bentonite is one kind of clay material which has 2:1 layer structure in which the octahedral sheet is sandwiched between two tetrahedral silica sheets, with water and metal cations existing between the spaces of the layers [5]. The layers are negatively charged and held together by charge-balancing counterions like $\mathrm{Ca}^{2+}$ and $\mathrm{Na}^{+}$. Natural bentonite has been known to have moderate adsorption capacity towards heavy metals and certain organic substances due to high cation exchange capacity (CEC), which is around 40-130 meq/100 $\mathrm{g}$ and high surface charge in their lattice structure [6]. However, due to its hydrophilic nature, natural bentonite is not a good adsorbent for many organic compounds. Therefore, modification of natural bentonite is necessary to increase its adsorption capacity. The combination of clay and other materials such as metal oxides and polymers has gained much attention from researchers in recent years. These clay based composite materials have excellent capability for removing various organic and inorganic contaminants [5,7].

The aim of this study was to use waste paper as raw material for the synthesis of NCC, and combining this NCC with bentonite to produce a nanocomposite material for removing $\mathrm{Pb}^{2+}$ and $\mathrm{Hg}^{2+}$ in single and binary systems. Improvement of extended Langmuir model to represent the adsorption isotherms of the binary system was also given in this study. The adsorption performance of the adsorbents was also tested. The mechanism of the adsorption was investigated from isotherm and thermodynamic viewpoints.

\section{Materials and methods}

\subsection{Materials}

Waste printing paper used in this study was obtained from our laboratory. The ink type for printing in this waste paper was toner from HP LaserJet Q7553A. Bentonite was obtained from Pacitan, East Java, Indonesia. The cation exchange capacity of this natural bentonite was $44.7 \mathrm{meq} / 100 \mathrm{~g}$. The chemical composition of natural bentonite was analyzed using PANalytical MiniPal QC energy dispersive X-ray fluorescence, and the results are as follows: $\mathrm{Al}_{2} \mathrm{O}_{3}=19.21 \%, \mathrm{SiO}_{2}=61.98 \%, \mathrm{Na}_{2} \mathrm{O}=2.22 \%, \mathrm{CaO}=3.59 \%$, $\mathrm{K}_{2} \mathrm{O}=1.78 \%, \mathrm{MgO}=1.98 \%, \mathrm{Fe}_{2} \mathrm{O}_{3}=2.97 \%, \mathrm{MnO}=0.22 \%$, and $\mathrm{TiO}_{2}=0.09 \%$. Analytical grade $\mathrm{NaOH}, \mathrm{HCl}, \mathrm{KNO}_{3}, \mathrm{~Pb}\left(\mathrm{NO}_{3}\right)_{2}, \mathrm{HgCl}_{2}$, chloroform, dimethyl sulfoxide, sulfuric acid, hydrogen peroxide, were used without further purification.

\subsection{Pretreatment of waste paper and bentonite}

Waste paper ( $5 \mathrm{~g}$ ) was soaked in tap water overnight and shredded using a blender. The shredded paper was then deinked with $100 \mathrm{ml}$ organic solvent that was 30\% chloroform (99\% purity)

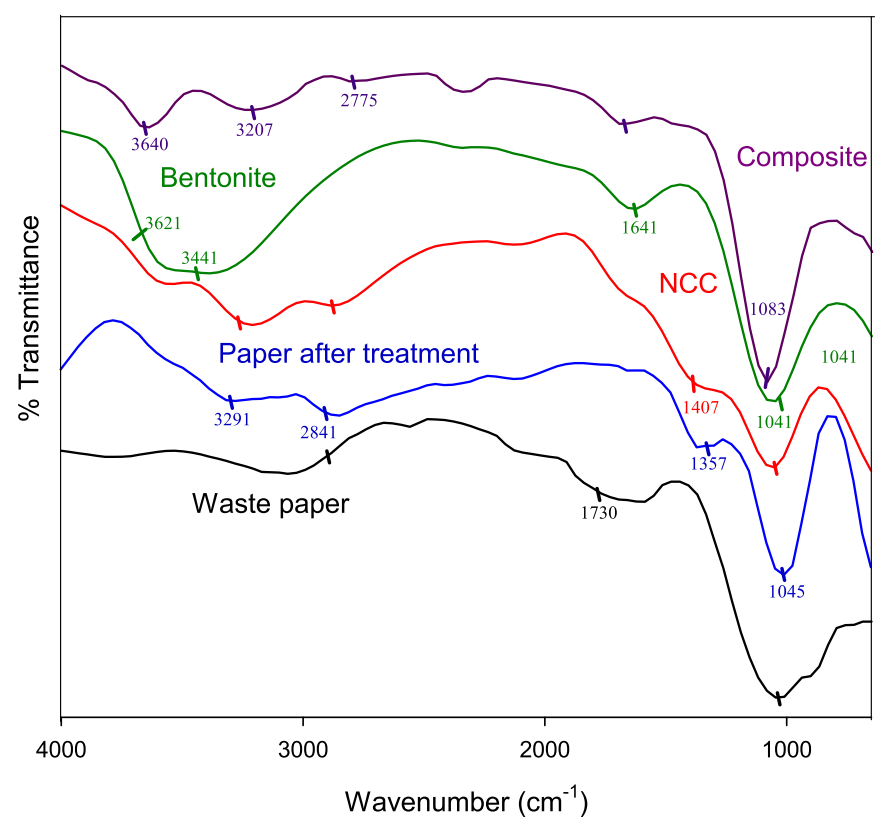

Fig. 1. ATR-FTIR result of waste paper, paper after treatment, bentonite, NCC, and composite.

and $70 \%$ dimethyl sulfoxide (99.7\% purity). Deinking was conducted under continuous stirring for $2 \mathrm{~h}$ at room temperature. Subsequently, the solution was sonicated for $15 \mathrm{~min}$, and the waste paper was filtered. The collected waste paper was dried in an oven overnight and kept in a desiccator for further use.

Before use, bentonite was purified in $30 \%$ hydrogen peroxide solution at room temperature for $24 \mathrm{~h}$ under continuous stirring to remove organic impurities. The weight ratio of bentonite and hydrogen peroxide solution was 1:5. Then the mixture was heated in boiling water for $2 \mathrm{~h}$ to remove excess hydrogen peroxide. The purified bentonite was separated from the solution by centrifugation and washed with distilled water, then dried at $110^{\circ} \mathrm{C}$ for $24 \mathrm{~h}$.

\subsection{Preparation of NCC/Bentonite composite}

The deinked waste paper ( $1 \mathrm{~g}$ ) was dissolved in $1 \mathrm{M} \mathrm{NaOH}(9 \mathrm{~g})$ to remove impurities and swell the cellulose fiber. The solution was stirred for $3 \mathrm{~h}$ at room temperature and dried in an oven at $50{ }^{\circ} \mathrm{C}$ for $6 \mathrm{~h}$. Then $1 \mathrm{~g}$ of waste paper was treated with $20 \mathrm{ml}$ of $64 \mathrm{wt} . \%$ $\mathrm{H}_{2} \mathrm{SO}_{4}$ at $45^{\circ} \mathrm{C}$ for $60 \mathrm{~min}$ under continuous stirring. After hydrolysis, the solid and liquid were separated by centrifugation (9503 g, $10 \mathrm{~min}$ ). The turbid supernatant was collected and placed in a dialysis tube for 3 days. The suspension was sonicated for $30 \mathrm{~min}$ in an ice-water bath to avoid overheating and kept in a $-20{ }^{\circ} \mathrm{C}$ refrigerator for $24 \mathrm{~h}$. Subsequently, the suspension was freeze-dried to obtain the NCC powder.

Preparation of NCC - bentonite nanocomposite was conducted according to the previous method [8] with modifications. Bentonite $(0.6 \mathrm{~g})$ was dispersed in DI water $(30 \mathrm{ml})$, stirred for $1 \mathrm{~h}$ and subsequently sonicated for $1 \mathrm{~h}$. The bentonite was added to $0.1 \%$ of NCC dispersion ( $30 \mathrm{~g}$ ) and stirred for $24 \mathrm{~h}$. Then the solution was sonicated for $1 \mathrm{~h}$. The nanocomposite formed was poured into a polystyrene Petri dish and oven dried at $50{ }^{\circ} \mathrm{C}$ for 1 day.

\subsection{Characterization}

Field emission scanning electron microscope (FESEM, JEOL JSM$6500 \mathrm{~F}$ ) was employed for obtaining the surface morphology of 

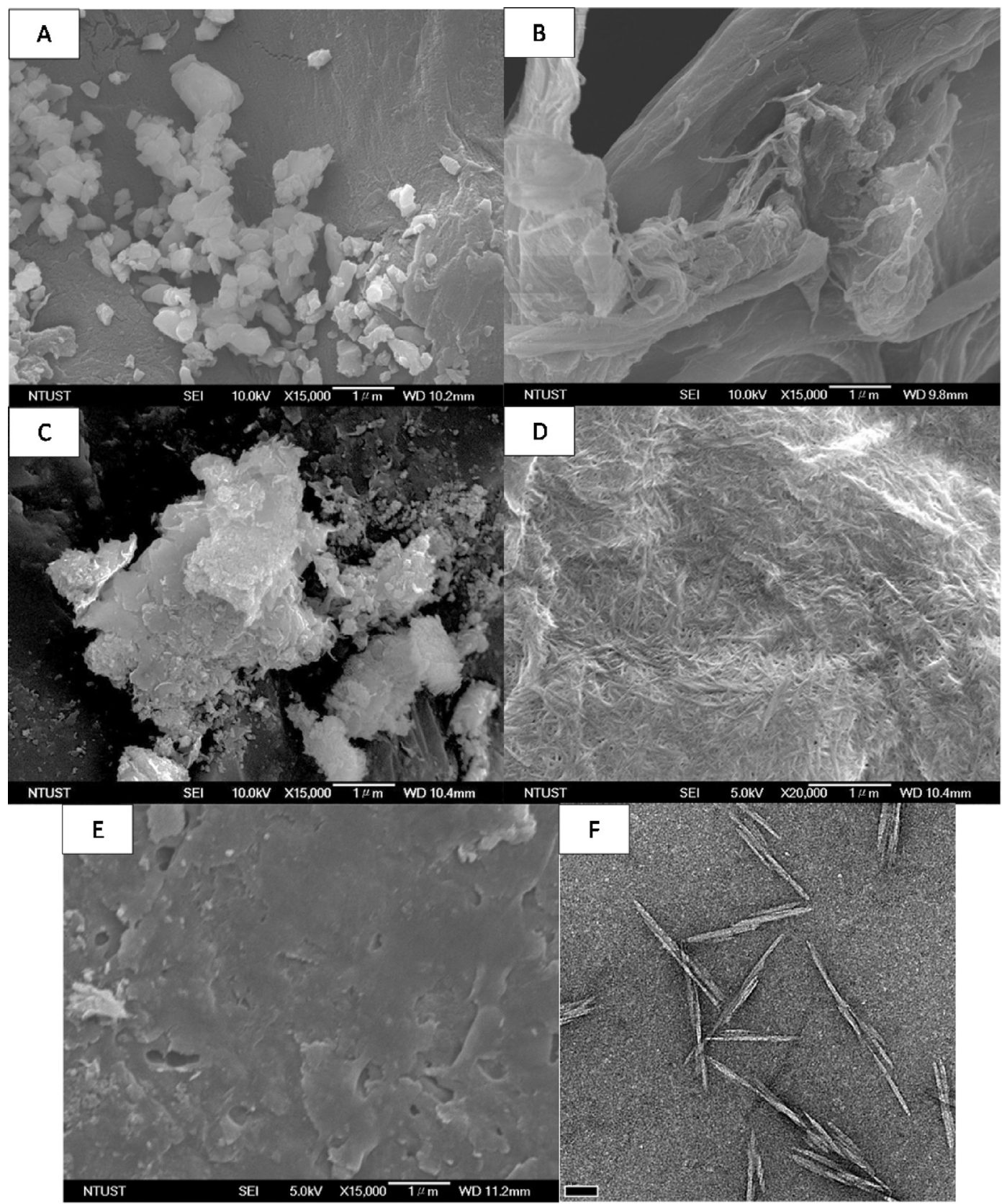

Fig. 2. Morphological image of (A) waste paper, (B) paper after treatment, (C) bentonite, (D) NCC, (E) composite, and (F) TEM of NCC.

samples. Prior to FESEM imaging, the sample was coated with a thin layer of platinum by a fine auto coater (JFC-1600, JEOL, Ltd., Japan) for $90 \mathrm{~s}$ in an argon atmosphere. The FESEM analysis was conducted at $10 \mathrm{kV}$ and $15 \mathrm{kV}$ with $10.4 \mathrm{~mm}$ working distance. Transmission electron microscope (TEM, Tecnai F20 G2 FEI-TEM) was conducted at $80 \mathrm{kV}$ to know the NCC morphology. The sample was prepared on a 300 mesh $\mathrm{Cu}$ grids with $2 \%$ uranyl acetate for staining. The attenuated total reflectance (ATR) FTIR (Bio-Rad Model FTS-3500) analysis was operated in the frequency range of $4000-650 \mathrm{~cm}^{-1}$ with $4 \mathrm{~cm}^{-1}$ scanning resolution, and the signal was accumulated from 100 scans. X-ray diffraction (XRD, Philips X'pert X-ray Diffractometer) patterns were acquired at $40 \mathrm{kV}$ and $30 \mathrm{~mA}$ using a monochromatic high-intensity $\mathrm{Cu} K \alpha_{1}$ radiation $(\lambda=0.15405 \mathrm{~nm})$. The surface charge of NCC, bentonite, and composite were determined using a zeta meter (Zeta Potential Analyzer, Brookhaven
90Plus). The thermal stability of NCC, bentonite, and composite was determined by thermal gravimetry analysis (TGA) using a Perkin Elmer Diamond TG/DTA thermal analyzer with a heating and cooling rate of $10^{\circ} \mathrm{C} \mathrm{min}^{-1}$ up to $600{ }^{\circ} \mathrm{C}$ under continuous nitrogen gas flow of $150 \mathrm{ml} \mathrm{min}{ }^{-1}$. Sample mass in each experiment was about $5 \mathrm{mg}$.

\subsection{Adsorption experiment}

Adsorption of lead and mercury was conducted in batch mode. For single system, a stock solution of $\mathrm{Pb}$ (II) or $\mathrm{Hg}$ (II) was prepared by dissolving $159.85 \mathrm{mg}$ of $\mathrm{Pb}\left(\mathrm{NO}_{3}\right)_{2}$ or $135.36 \mathrm{mg}$ of $\mathrm{HgCl}_{2}$ into a liter of distilled water. The adsorption experiments were conducted by introducing various masses $(0.1-2.0 \mathrm{~g})$ of NCC, bentonite, nanocomposite into a series of conical flasks containing $50 \mathrm{ml}$ of 


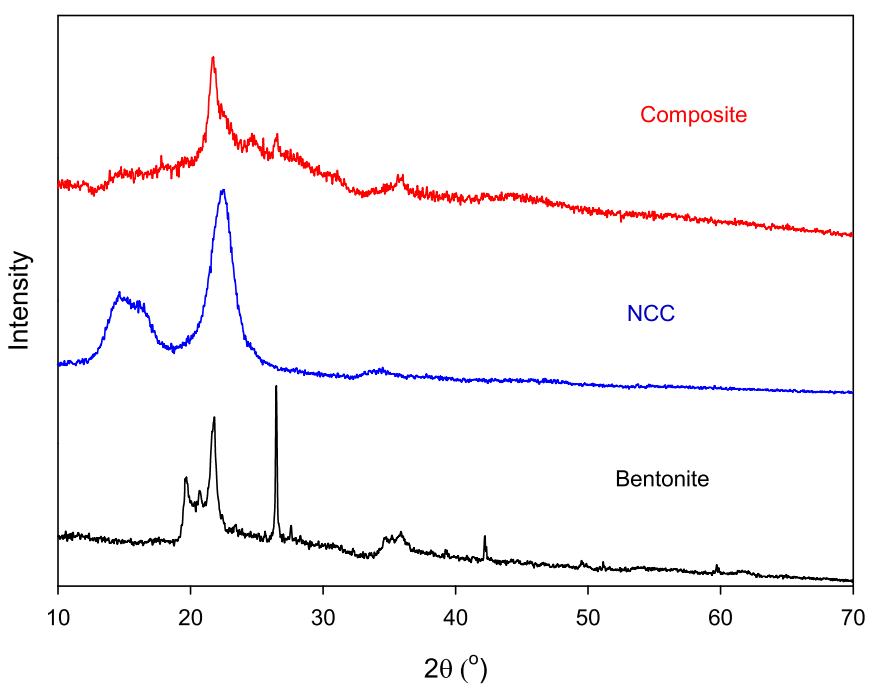

Fig. 3. X-ray diffraction of adsorbents.

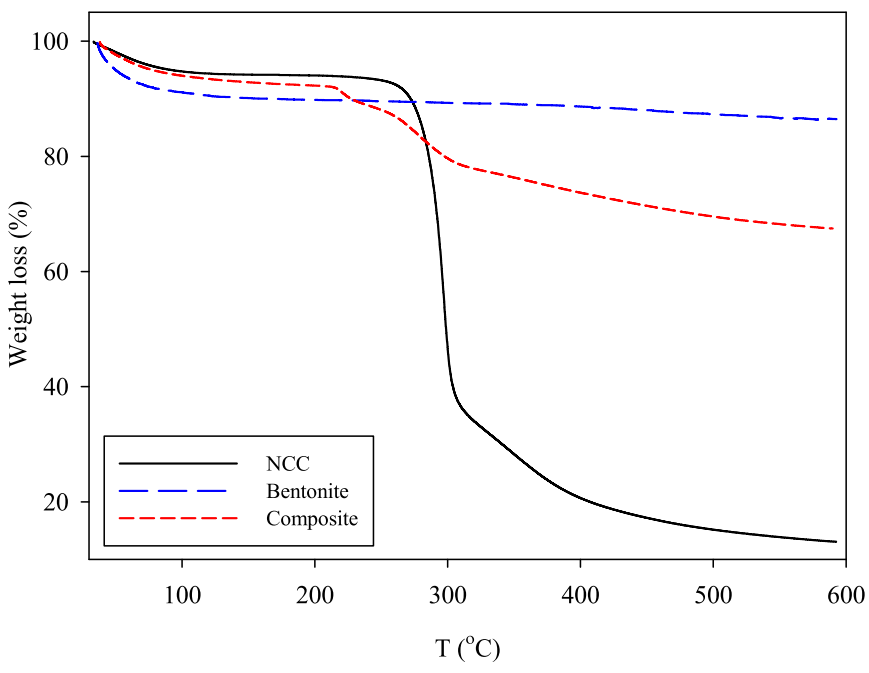

Fig. 4. TGA curve for the characterization of bentonite, NCC and composite.

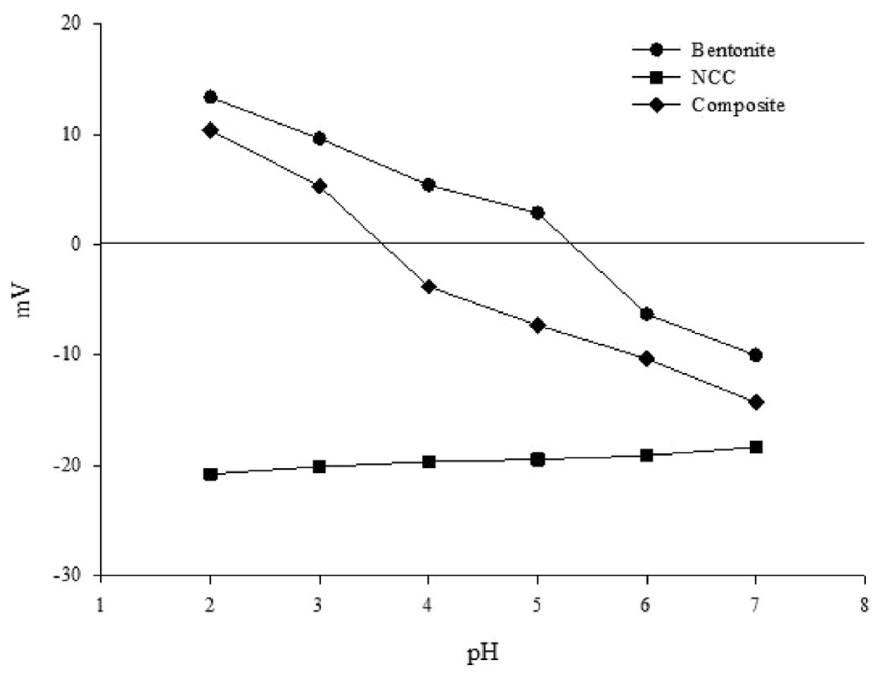

Fig. 5. Surface charge of adsorbents. lead or mercury at a certain $\mathrm{pH}$ value. The $\mathrm{pH}$ was previously fixed at a range of 2-7 by adding $0.1 \mathrm{M} \mathrm{HCl}$ or $\mathrm{NaOH}$ solution into the heavy metal solution. The effect of temperature on adsorption isotherm was studied by carrying out the adsorption at 30,40, and $50{ }^{\circ} \mathrm{C}$. After equilibrium condition was reached, the solution was separated from the adsorbent by centrifugation (6082 g, $10 \mathrm{~min}$ ). The final concentration of $\mathrm{Pb}$ (II) and $\mathrm{Hg}$ (II) was measured using ICPOES. Adsorbed $\mathrm{Pb}(\mathrm{II})$ and $\mathrm{Hg}(\mathrm{II})$ at equilibrium condition per unit mass of adsorbent $\left(q_{e}\right)$ was calculated using the following equation:

$q_{e}=\frac{C_{o}-C_{e}}{m} V$

where $q_{e}$ is the amount of $\mathrm{Pb}$ (II) or $\mathrm{Hg}$ (II) adsorbed on the adsorbent (mmol/g) at equilibrium condition, $C_{o}$ and $C_{e}$ are the initial and equilibrium concentrations $(\mathrm{mmol} / \mathrm{L})$, respectively. $V$ is the volume of solution ( $\mathrm{L})$, and $m$ is the mass of adsorbent ( $\mathrm{g}$ ).

For a binary system, a known amount of $\mathrm{Pb}(159.85 \mathrm{mg}$, $319.70 \mathrm{mg}$, $479.55 \mathrm{mg}$ ) was added into $1 \mathrm{~L} \mathrm{Hg}$ solution (135.36 mg). The binary adsorption was conducted at $30^{\circ} \mathrm{C}$ and $\mathrm{pH} 2,6$ and 5 for $\mathrm{NCC}$, bentonite and composite, respectively. The amount of $\mathrm{Pb}(\mathrm{II})$ and $\mathrm{Hg}(\mathrm{II})$ adsorbed at equilibrium condition per unit mass of adsorbent $\left(q_{e}\right)$ was calculated using the following equation:

$q_{e, i / j}=\frac{\left(C_{o, i / j}-C_{e, i / j}\right)}{m} V$

where $q_{e, i}$ and $q_{e, j}$ are the amount of $\mathrm{Pb}(\mathrm{II})$ and $\mathrm{Hg}(\mathrm{II})$ adsorbed on the adsorbent ( $\mathrm{mmol} / \mathrm{g}$ ) at equilibrium condition, respectively, $C_{o, i / j}$ and $C_{e, i / j}$ are the initial and equilibrium concentrations $(\mathrm{mmol} / \mathrm{L})$, respectively.

\section{Results and discussion}

\subsection{ATR FTIR analysis}

ATR-FTIR is the most widely used technique for characterization of materials based on the vibrations of atoms within the molecules. Fig. 1 represents the spectra of waste paper, deinked waste paper, purified bentonite, NCC, and composite. Both waste paper and deinked waste paper spectra show the cellulose characteristic peaks as indicated by $\mathrm{C}-\mathrm{O} / \mathrm{C}-\mathrm{C}$ stretching $\left(1045 \mathrm{~cm}^{-1}\right), \mathrm{C}-\mathrm{H}$ bonding $\left(1357 \mathrm{~cm}^{-1}\right)$, and $\mathrm{CH}_{2}$ symmetrical stretching $\left(2841 \mathrm{~cm}^{-1}\right)$ $[9,10]$. From these spectra, there are two prominent different peaks. The peak at $1730 \mathrm{~cm}^{-1}$ for waste paper corresponds to carbonyl band that is usually found in toner such as styrene acrylate copolymer [11,12]. The appearance of $-\mathrm{OH}$ group $\left(3291 \mathrm{~cm}^{-1}\right)$ in deinked waste paper can be explained by the removal of toner that previously covered up the -OH groups on the cellulose fiber [9]. All the characteristics of cellulose from deinked waste paper are retained in NCC. New peak appears for NCC in $1407 \mathrm{~cm}^{-1}$ which indicates the presence of sulfate esters due to sulfuric acid hydrolysis. FTIR spectrum of bentonite shows the characteristics of montmorillonite clays as demonstrated by $\mathrm{Al}(\mathrm{Mg})-\mathrm{OH}$ stretching (3612 $\left.\mathrm{cm}^{-1}\right), \mathrm{H}-\mathrm{O}-\mathrm{H}$ stretching $\left(3441 \mathrm{~cm}^{-1}\right),-\mathrm{OH}$ bending for adsorbed water $\left(1641 \mathrm{~cm}^{-1}\right)$ and $\mathrm{Si}-\mathrm{O}-\mathrm{Si}$ stretching of the tetrahedral sheet $\left(1041 \mathrm{~cm}^{-1}\right)[5,13,14]$. The characteristic peaks of NCC and bentonite seem to be retained as indicated in the nanocomposite spectrum. The wavenumber $1083 \mathrm{~cm}^{-1}$ indicates the $\mathrm{Si}-\mathrm{O}$ in bentonite, the shifting of the peak of silica from $1041 \mathrm{~cm}^{-1}$ to $1083 \mathrm{~cm}^{-1}$ was possibly due to the exfoliated off the tetrahedral sheet by NCC. The wavenumber of $\mathrm{Al}-\mathrm{OH}-\mathrm{Mg}$ appears at $3640 \mathrm{~cm}^{-1}$ which was slightly altered from $3612 \mathrm{~cm}^{-1}$. The wavenumbers of $2775 \mathrm{~cm}^{-1}$ and $3207 \mathrm{~cm}^{-1}$ corresponded to the $\mathrm{C}-\mathrm{H}$ bond and bonded $\mathrm{OH}$ from NCC, respectively. 

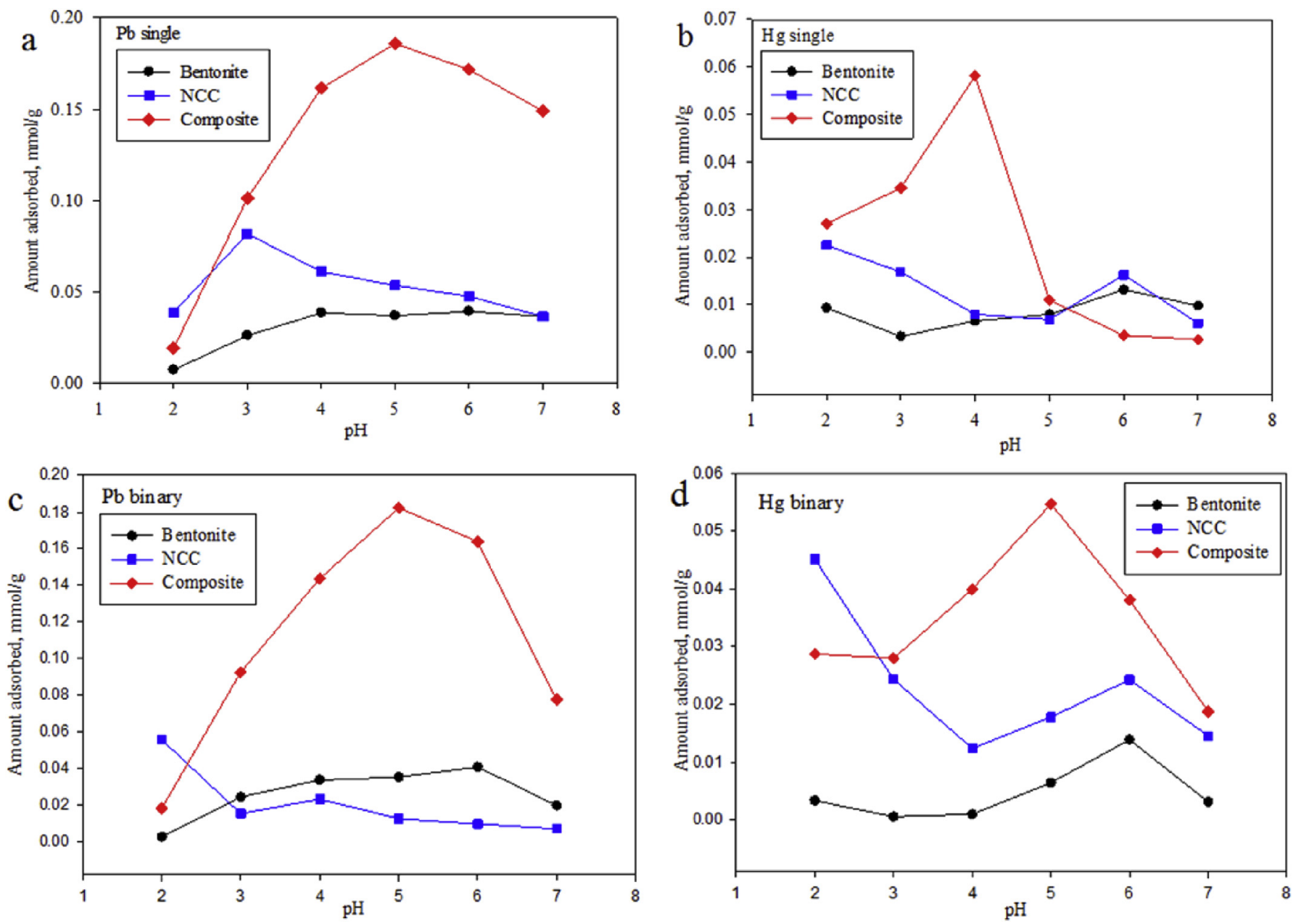

Fig. 6. Effect of $\mathrm{pH}$ on the adsorption of (a) Pb single, (b) $\mathrm{Hg}$ single, (c) Pb binary and (d) $\mathrm{Hg}$ binary.

\subsection{Surface morphology analysis}

The surface morphologies of waste paper, deinked waste paper, bentonite, NCC, and nanocomposite are shown in Fig. 2. It can be seen from the image of waste paper that there were toner particles on the surface of cellulose fiber (Fig. 2a). After pretreatment, toner particles were removed and the fiber seems to be swollen due to $\mathrm{NaOH}$ pretreatment (Fig. 2b). The swelling of cellulose fibers helped to create homogeneous NCC particles. The SEM image of bentonite (Fig. 2c) reveals that the surface topography of bentonite consists of stacked sheets with heterogeneous surfaces. It can be seen from the surface topography of NCC (Fig. 2d) that NCC has a crystal structure. The TEM result of NCC (Fig. $2 \mathrm{f}$ ) indicates that NCC possesses a rod crystal morphology with length around $157 \mathrm{~nm}$. The morphology of composite (Fig. 2e) is similar to the bentonite morphology but with a smoother surface.

\subsection{X-ray diffraction}

The crystalline phase of materials was observed by XRD. The characteristic peaks of montmorillonite in bentonite (Fig. 3) are at $19.7^{\circ}$ and $22^{\circ}$. The other diffraction peaks belong to quartz $\left(26.5^{\circ}\right.$, $42.1^{\circ}$, and $51^{\circ}$ ) and $\mathrm{FeCaCO}_{3}\left(35.8^{\circ}\right)$ [15]. Crystal plane of 200 at $22.3^{\circ}$ represents the crystalline part of cellulose in NCC diffraction graph, the broad peak around $14^{\circ}-16.5^{\circ}$ indicates the crystal plane of 110 [16]. Continuous and broad peak was observed in XRD pattern of composite between $21.7^{\circ}$ and $23^{\circ}$ denoting the combination of the crystalline part between bentonite and NCC which have been exfoliated within each other.

\subsection{Thermal gravimetry analysis (TGA)}

The thermal characteristic of NCC, bentonite, and composite was characterized using thermogravimetry analysis, and the results are given in Fig. 4. TGA result of NCC shows that three different stages of weight loss occurred during the heating process. The first stage of weight loss was due to the evaporation of moisture content $\left(30-200^{\circ} \mathrm{C}\right)$ and it was found that the moisture content of NCC was around $6.5 \%$. The second stage of the weight loss occurred at $245-315{ }^{\circ} \mathrm{C}$. In this stage, the weight loss of the sample $(\sim 58.3 \%)$ was mostly due to thermal degradation (dehydration and depolymerization of cellulose). In the last stage, the weight loss was mostly due to the carbonization of intermediate chars [17]. For bentonite, it was observed that there are two stages in TGA curve. The first stage corresponds to the evaporation of moisture content and the second stage was due to the dehydroxylation of aluminosilicate in bentonite [18]. The thermogravimetric curve of the composite shows a similar trend to that of the thermal degradation of the composite of NCC and bentonite, with the degradation of cellulose starting at between 215 and $315{ }^{\circ} \mathrm{C}$ and dehydroxylation phase at $315-590^{\circ} \mathrm{C}$. 


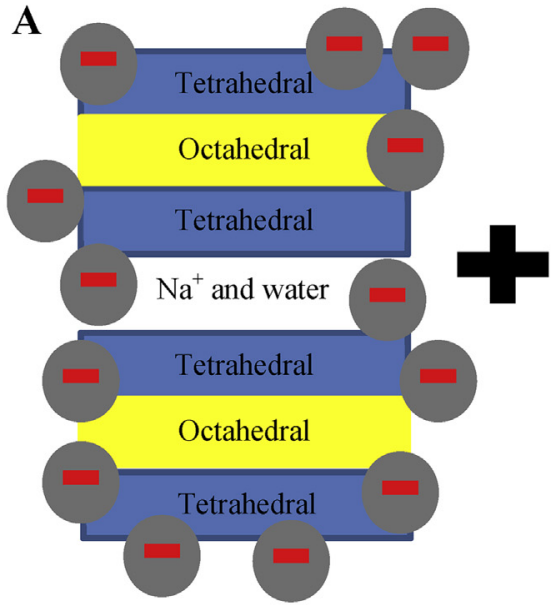

B
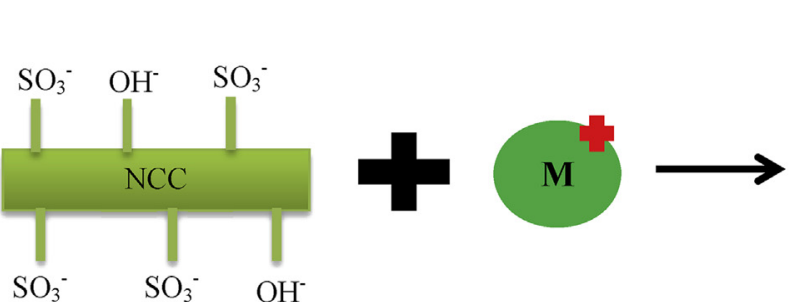
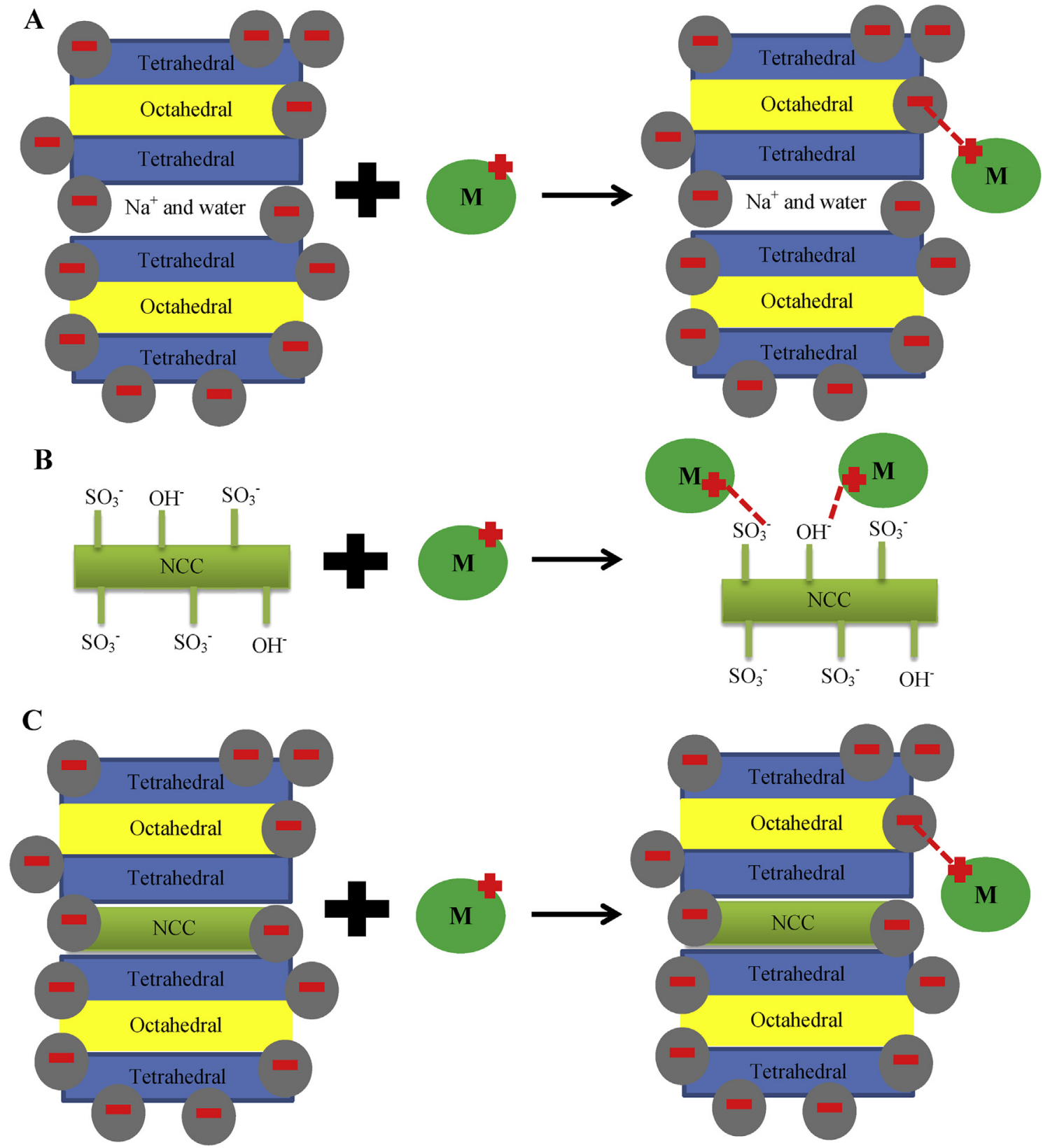

Fig. 7. Adsorption mechanism between each adsorbents (A: bentonite, $\mathrm{B}$ : NCC, C: composite) and metal ( $\mathrm{M}^{+}$: $\mathrm{Pb}$ or $\mathrm{Hg}$ ).

\subsection{Zeta potential}

Zeta potential of each adsorbent was measured to obtain the isoelectric point. From Fig. 5, it can be seen that the surface charge of bentonite and composite is $\mathrm{pH}$ dependent. The isoelectric point is where the adsorbent has no charge at specific $\mathrm{pH}$ value. Isoelectric points for bentonite and composite are at pH 5.4 and 3.6, respectively. The surface charge of NCC is pH independent as seen in Fig. 5. The surface charge of NCC is almost constant $(\sim-20 \mathrm{mV})$ at all $\mathrm{pH}$ which indicates excellent stability of NCC at various $\mathrm{pH}$.

\subsection{Effect of $p H$}

$\mathrm{pH}$ has been known to have a strong influence on the adsorption of heavy metals onto various adsorbents. Fig. 6 depicts the effect of
$\mathrm{pH}$ on the adsorption of $\mathrm{Pb}(\mathrm{II})$ and $\mathrm{Hg}$ (II) onto bentonite, NCC, and nanocomposite. The $\mathrm{pH}$ optimum for adsorption of $\mathrm{Pb}$ (II) and $\mathrm{Hg}$ (II) onto bentonite both in the single or binary system was achieved at $\mathrm{pH}$ 6. For NCC in single system, the $\mathrm{pH}$ optimum for adsorption of $\mathrm{Hg}$ (II) was $\mathrm{pH} 2$ while for $\mathrm{Pb}$ (II) was $\mathrm{pH} 3$. For the adsorption of $\mathrm{Hg}$ (II) and $\mathrm{Pb}$ (II) onto nanocomposite, the $\mathrm{pH}$ optimum in single system for adsorption $\mathrm{Hg}$ (II) was $\mathrm{pH} 4$, while for $\mathrm{Pb}(\mathrm{II})$ was $\mathrm{pH}$ 5. In binary adsorption process, the optimum pH for NCC was 2 and 5 for composite. Slight change in the optimum $\mathrm{pH}$ of binary adsorption process for NCC and composite denotes that surface charge of NCC has a quite significant role in the binary adsorption, as discussed previously that NCC has good stability at the various condition of $\mathrm{pH}$.

The isoelectric point of bentonite is at $\mathrm{pH} 5.4$ as indicated in Fig. 5. Below this isoelectric point, the bentonite is positively charged while above this point the bentonite is negatively 

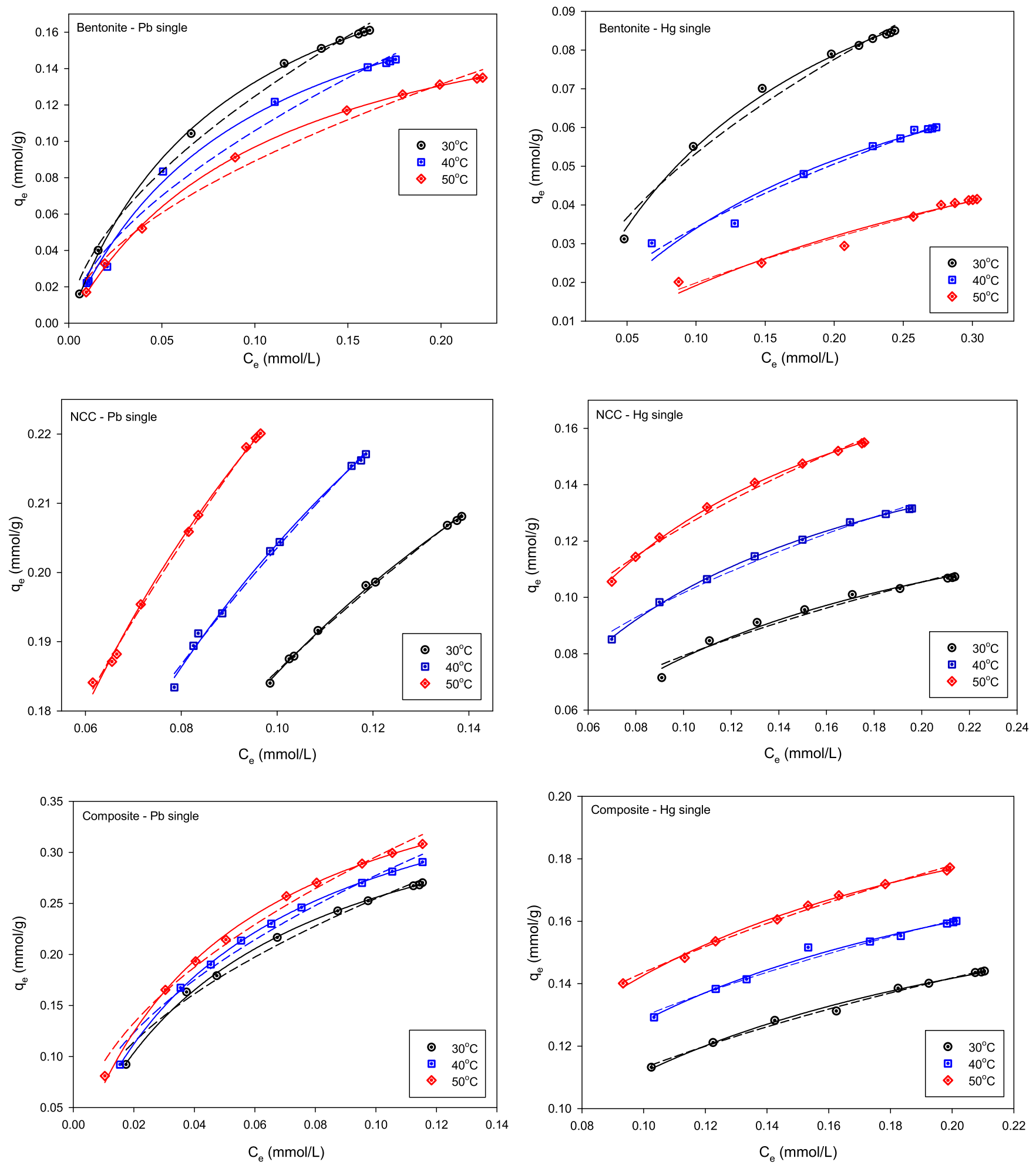

Fig. 8. Adsorption isotherms of single system in 30,40 , and $50{ }^{\circ} \mathrm{C}$ (solid line: Langmuir fitting, dashed line: Freundlich fitting).

charged. At $\mathrm{pH} \mathrm{6,} \mathrm{lead} \mathrm{ions} \mathrm{are} \mathrm{present} \mathrm{in} \mathrm{the} \mathrm{forms} \mathrm{of} \mathrm{Pb}(\mathrm{II})$ and $\mathrm{PbOH}^{+}$. Since the surface of the bentonite is negatively charged, therefore, electrostatic interaction between lead cations and the surface of bentonite occurred, resulting in the increased amount of lead cations adsorbed onto the surface of bentonite. A similar phenomenon also took place in the adsorption of $\mathrm{Hg}(\mathrm{II})$ onto bentonite. At $\mathrm{pH} \mathrm{6}$, the mercury ions exist in the forms of $\mathrm{HgOH}^{+}$ and $\mathrm{HgOHCl}[19,20]$ and the interaction between the surface of bentonite and $\mathrm{HgOH}^{+}$is electrostatic, while with $\mathrm{HgOHCl}$ it is through van der Waals force. 
Table 1

Langmuir and Freundlich parameters for single adsorption system at various temperatures.

\begin{tabular}{|c|c|c|c|c|c|c|c|c|}
\hline \multirow[t]{2}{*}{ Adsorbent } & \multirow[t]{2}{*}{ Adsorbate } & \multirow[t]{2}{*}{$\mathrm{T}\left({ }^{\circ} \mathrm{C}\right)$} & \multicolumn{3}{|c|}{ Langmuir parameters } & \multicolumn{3}{|l|}{ Freundlich parameters } \\
\hline & & & $q_{m}(\mathrm{mmol} / \mathrm{g})$ & $K_{L}(\mathrm{~L} / \mathrm{mmol})$ & $\mathrm{R}^{2}$ & $K_{F}\left((\mathrm{mmol} / \mathrm{g})(\mathrm{mmol} / \mathrm{L})^{1 / \mathrm{n}}\right)$ & $n$ & $\mathrm{R}^{2}$ \\
\hline \multirow[t]{6}{*}{ Bentonite } & \multirow[t]{3}{*}{$\mathrm{Pb}$} & 30 & 0.25 & 11.52 & 0.99 & 0.47 & 1.72 & 0.99 \\
\hline & & 40 & 0.22 & 10.50 & 0.99 & 0.41 & 1.67 & 0.98 \\
\hline & & 50 & 0.20 & 9.37 & 0.99 & 0.32 & 1.79 & 0.99 \\
\hline & \multirow[t]{3}{*}{$\mathrm{Hg}$} & 30 & 0.13 & 6.59 & 0.99 & 0.18 & 1.85 & 0.98 \\
\hline & & 40 & 0.10 & 4.65 & 0.95 & 0.13 & 1.77 & 0.98 \\
\hline & & 50 & 0.09 & 2.54 & 0.95 & 0.09 & 1.51 & 0.97 \\
\hline \multirow[t]{6}{*}{ NCC } & \multirow[t]{3}{*}{$\mathrm{Pb}$} & 30 & 0.30 & 15.51 & 0.99 & 0.42 & 2.83 & 0.99 \\
\hline & & 40 & 0.33 & 16.14 & 0.99 & 0.49 & 2.58 & 0.99 \\
\hline & & 50 & 0.35 & 18.19 & 0.99 & 0.57 & 2.42 & 0.99 \\
\hline & \multirow[t]{3}{*}{$\mathrm{Hg}$} & 30 & 0.16 & 9.68 & 0.98 & 0.20 & 2.43 & 0.96 \\
\hline & & 40 & 0.18 & 11.96 & 0.99 & 0.25 & 2.50 & 0.99 \\
\hline & & 50 & 0.22 & 13.31 & 0.99 & 0.31 & 2.54 & 0.99 \\
\hline \multirow[t]{6}{*}{ Composite } & \multirow[t]{3}{*}{$\mathrm{Pb}$} & 30 & 0.40 & 17.25 & 0.99 & 0.80 & 2.00 & 0.98 \\
\hline & & 40 & 0.43 & 17.46 & 0.99 & 0.88 & 1.99 & 0.98 \\
\hline & & 50 & 0.44 & 19.33 & 0.99 & 0.92 & 2.01 & 0.98 \\
\hline & \multirow[t]{3}{*}{$\mathrm{Hg}$} & 30 & 0.19 & 13.50 & 0.99 & 0.24 & 3.05 & 0.99 \\
\hline & & 40 & 0.21 & 15.13 & 0.99 & 0.26 & 3.26 & 0.98 \\
\hline & & 50 & 0.23 & 15.87 & 0.99 & 0.29 & 3.23 & 0.99 \\
\hline
\end{tabular}

In the case of the adsorption of heavy metals onto NCC, since the surface of the NCC is negatively charged at all $\mathrm{pH}$, the adsorption mechanism is obviously electrostatic interaction between negatively charged NCC and metal cations. The presence of hydroxyl and sulfonate functional groups on the surface of NCC also enhanced the adsorption capacity of NCC towards Pb(II) and $\mathrm{Hg}(\mathrm{II})$.

The combination of bentonite and NCC as nanocomposite greatly enhanced the adsorption removal of $\mathrm{Pb}$ (II) and $\mathrm{Hg}$ (II) as can be seen in Fig. 6. The mechanism of the adsorption of $\mathrm{Pb}(\mathrm{II})$ and $\mathrm{Hg}(\mathrm{II})$ onto nanocomposite is the electrostatic interaction between metal ions and negatively charged surface of the nanocomposite. In general, for all adsorbents the adsorption of $\mathrm{Pb}(\mathrm{II})$ is more preferable to $\mathrm{Hg}$ (II) (including in the binary system). Based on the electronegativity values ( 2.00 for $\mathrm{Hg}$ and 1.87 for $\mathrm{Pb}$ ), the adsorption behavior should be opposite, i.e. $\mathrm{Hg}(\mathrm{II})$ should be adsorbed easier onto the surface of the adsorbents than $\mathrm{Pb}(\mathrm{II})$ [21]. Since this adsorption phenomenon cannot be explained by the electronegativity of the metals, we will explain it further with the effect of van der Walls radius ( $150 \mathrm{pm}$ for $\mathrm{Pb}$ and $200 \mathrm{pm}$ for $\mathrm{Hg}$ ) which is defined as the half of the internuclear distance of two atoms [22]. With a larger van der Walls radius, the forces in mercury are weaker than in lead. Thus the chance of mercury to create higher affinity is better than lead. However the results (Fig. 6c and d) indicate that the adsorbents have better interaction with $\mathrm{Pb}(\mathrm{II})$ than $\mathrm{Hg}(\mathrm{II})$. Since the van der Walls radii concept also cannot explain this adsorption phenomenon, we will try another approach.

Pearson's principle states that hard acids prefer to bind to hard bases and soft acids to soft bases. $\mathrm{Hg}^{2+}$ is a soft acid while $\mathrm{Pb}^{2+}$ is a borderline acid [23]. For bentonite, interaction with $\mathrm{Pb}(\mathrm{II})$ is preferable because in its structure there are exchangeable cations (hard acid) and water (hard base) in the midst of bentonite layers, hence $\mathrm{Pb}(\mathrm{II})$ can form attractive forces with hard acid and a hard base. Since NCC has hydroxyl and sulfite anion which are hard base and borderline base, respectively and the $\mathrm{pH}$ is acid (2-3) which makes low $\mathrm{Hg}(\mathrm{II})$ affinity towards adsorbents hence adsorption is not as strong as in the case of $\mathrm{Pb}(\mathrm{II})$. The schematic diagram of this adsorption mechanism can be seen in Fig. 7.

\subsection{Adsorption isotherms in single system}

Various models have been developed to represent liquid phase adsorption equilibria data. The most common used adsorption isotherms models are Langmuir and Freundlich. Both isotherm equations consist of two parameters. Langmuir adsorption isotherm is based on assuming homogeneous surface and energy on the adsorbent surface, while Freundlich is an empirical model for heterogeneous systems. Both models have been extensively used to represent huge numbers of adsorption experimental data since these equations are simple and can fit the data in a specific concentration range. Langmuir (Eq. (3)) and Freundlich (Eq. (4)) models are mathematically expressed as follows:

$q_{e}=q_{\mathrm{m}} \frac{K_{L} C_{e}}{1+K_{L} C_{e}}$

$q_{e}=K_{F} C_{e}^{1 / n}$

where $q_{m}$ is the Langmuir constant which indicates the maximum adsorption capacity of the adsorbent with monolayer surface coverage $(\mathrm{mmol} / \mathrm{g})$, and $K_{L}$ is the adsorption affinity constant (L/ $\mathrm{mmol}) . K_{F}$ is the Freundlich constant which expresses the adsorption capacity $\left[(\mathrm{mmol} / \mathrm{g})(\mathrm{mmol} / \mathrm{L})^{1 / \mathrm{n}}\right]$ and $n$ is the dimensionless unit representing the surface heterogeneity. A higher $n$ reflects that the adsorption system is more heterogeneous.

The adsorption experimental data were fitted to the adsorption equations using nonlinear regression fitting, and the results are shown in Fig. 8. It can be seen that the fitting results (Table 1) indicate that Langmuir model fits the experimental data better than Freundlich model. Correlation coefficient factors $\left(R^{2}\right)$ for Langmuir models are around 0.95-0.99. From Table 1 it can be seen that all of the parameters of Langmuir and Freundlich models are temperature dependent. For heavy metals - bentonite system, $q_{\max }$ and $K_{L}$ decreased with increasing temperature, while for other systems, these parameters increase with the increase of temperature. The increase of uptake amount with temperature is a strong indication that chemisorption is the control mechanism of the adsorption process. Physical adsorption is the main control mechanism of the adsorption of $\mathrm{Pb}(\mathrm{II})$ and $\mathrm{Hg}$ (II) onto bentonite.

In chemisorption mechanism, the adsorbate molecules are strongly attached to the surface of the adsorbent. This phenomenon is indicated by $K_{L}$ in Langmuir equation. The stronger the interaction between adsorbate and adsorbent, the higher the value of $K_{L}$. The values of $K_{L}$ for NCC and nanocomposite systems 

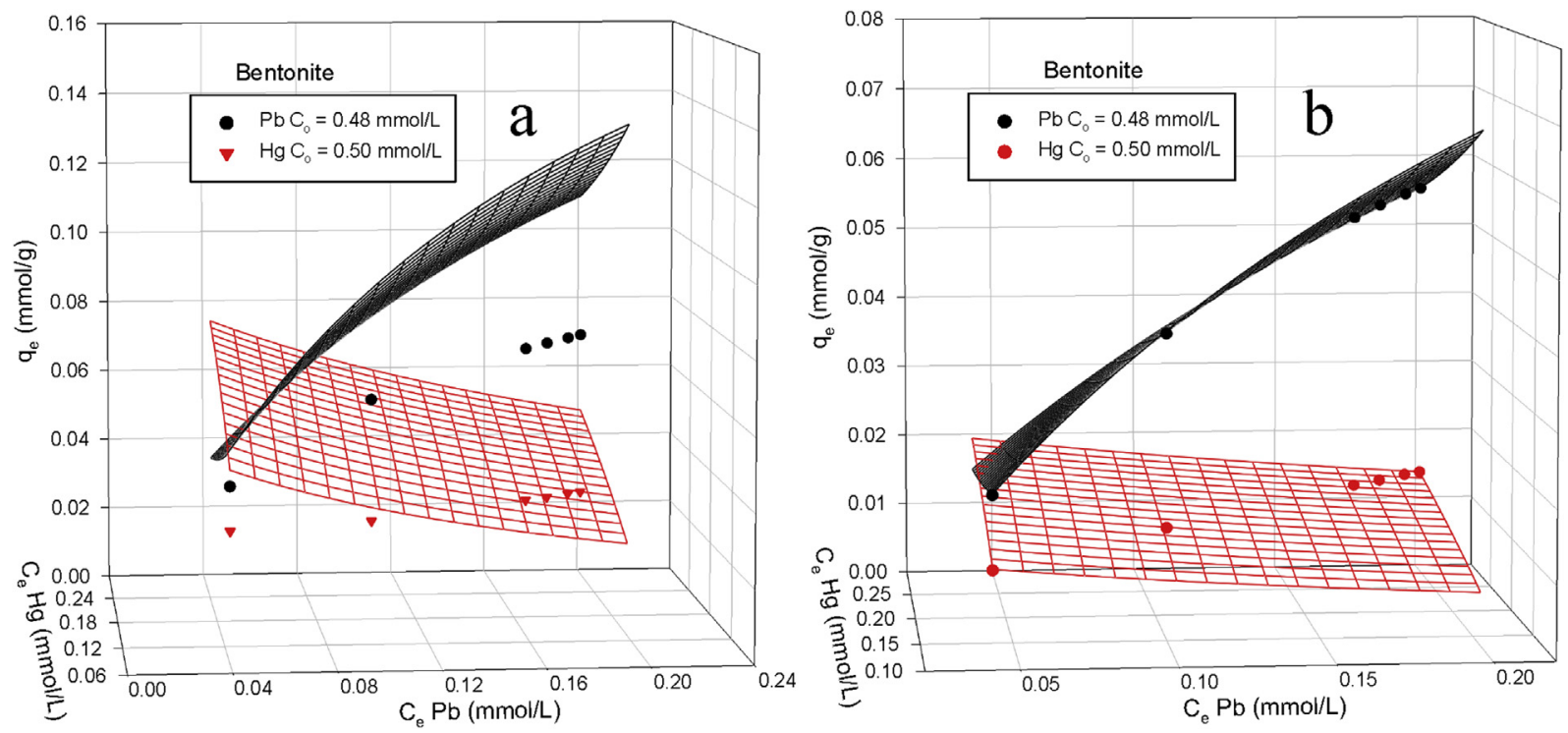

Fig. 9. Plotting of experimental data against (a) original extended Langmuir and (b) modified extended Langmuir.

are higher than those in heavy metals - bentonite system as indicated in Table 1. Both NCC and nanocomposite possess hydroxyl and sulfonate functional groups on their surface, and usually, the binding of these functional groups and heavy metal ions are mostly through electrostatic interaction which is much stronger interaction than van der Walls force. The basic structure of bentonite is a layer consisting of two inward-pointing tetrahedral sheets with a central alumina octahedral sheet $(2: 1)$. In this 2:1 layer structure, water, and other cations exist and these layers also have intermolecular forces which can be much stronger than the interaction of heavy metal molecules, and the surface layer of bentonite, hence heavy metals ions are not able to penetrate into Stern-Gouy layer between those layers [24]. Therefore, lower adsorption affinity was observed for heavy metals - bentonite system.

\subsection{Adsorption isotherms of binary system: improvement of extended Langmuir model}

Among of the available models for multicomponent adsorption, the extended Langmuir possibly is the most widely used one to describe binary adsorption data, because it is simple and can represent the experimental data comparatively better than other models. The extended Langmuir is expressed as follows:

$q_{e, i}=q_{\mathrm{m}, i} \frac{K_{L, i} C_{e, i}}{1+\Sigma_{j=1}^{n} K_{L, i} C_{e, i}}$

For binary system, Eq. (5) becomes

$q_{e, 1}=q_{\mathrm{m}, 1} \frac{K_{L, 1} C_{e, 1}}{1+K_{L, 1} C_{e, 1}+K_{L, 2} C_{e, 2}}$

$q_{e, 2}=q_{\mathrm{m}, 2} \frac{K_{L, 2} C_{e, 2}}{1+K_{L, 1} C_{e, 1}+K_{L, 2} C_{e, 2}}$

where $q_{m, i}$ and $K_{L, i}$ in Eqs. (6) and (7) are Langmuir constants which are obtained from the fitting of adsorption experimental data of single system or pure component. This model has been developed for competitive multicomponent adsorption with respect to the energy of adsorption in system [25]. In real multicomponent adsorption system, competition between adsorbates molecules for active sites always occur, and this phenomenon usually acts as the controlling mechanism. However, the shortcoming of the original extended Langmuir model is that it does not consider the competition of adsorbate molecules on the active adsorption sites of adsorbent. The absence of the competition between the adsorbates molecules in this model often results in overestimate of the theoretical values of the isotherm [26]. Thus an improvement for this model is proposed in this work to predict the binary components adsorption equilibria. Regarding the competition of adsorption of molecules onto one of the available active surface sites, the Langmuir constants $q_{m}$ and $K_{L}$ are modified in terms of fractional loading as follows:

$q_{m, 1(\mathrm{bin})}=q_{\mathrm{m}, 1} \theta_{1}$

$q_{m, 2 \text { (bin) }}=q_{\mathrm{m}, 2} \theta_{2}$

$K_{L, 1(\text { bin })}=K_{L, 1(\text { single })} \times\left(\frac{Q_{1} \theta_{1}}{Q_{1} \theta_{1}+Q_{2} \theta_{2}}\right)$

$K_{L, 2(\text { bin })}=K_{L, 2(\text { single })} \times\left(\frac{Q_{2} \theta_{2}}{Q_{1} \theta_{1}+Q_{2} \theta_{2}}\right)$

where $\theta_{1}$ and $\theta_{2}$ are the fractional loading of component 1 and 2 in the surface of adsorbent, respectively, while $Q_{1}$ and $Q_{2}$ are the heat of adsorption of component 1 and 2, respectively. As mentioned in the previous section, the Langmuir affinity constant measures how strong the adsorbate molecules are attached or attracted onto the surface of the adsorbent. Basically, the fractional loading $\theta$ and heat of adsorption $Q$ will influence the Langmuir affinity constant as indicated in Eqs. (10) and (11). In Eqs. (10) and (11), the competition between adsorbate molecules is expressed as the ratio of the multiplication between the heat of adsorption and fractional loading of certain adsorbate to the summation of those values for both components. Taking into account that the competition occurred in the adsorption system, adsorption affinity in the binary system should be lower than in single system. The introduction of fractional loading in Eqs. (10) and (11) indicates that the contribution of surface coverage of a 

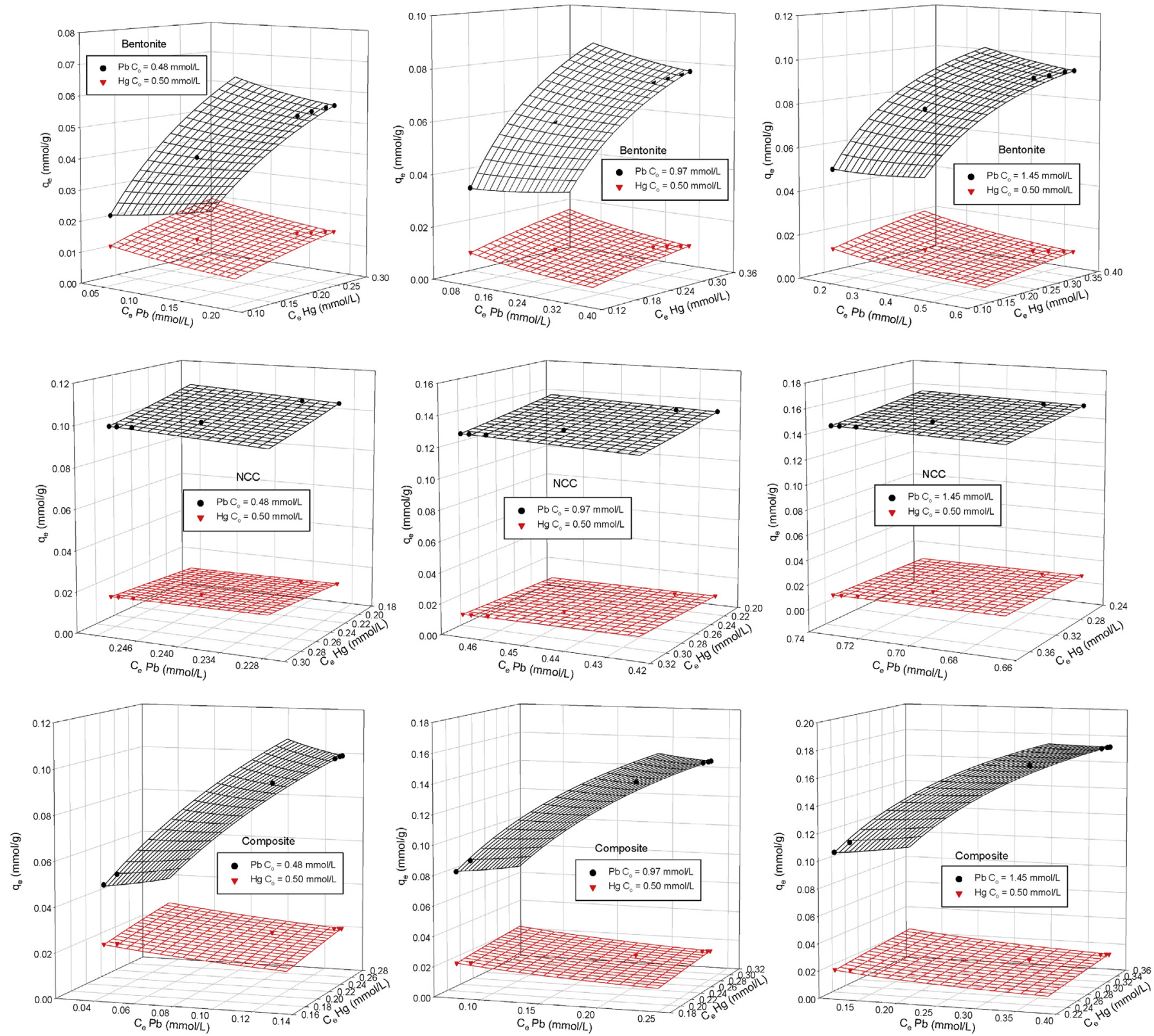

Fig. 10. Modified extended Langmuir isotherm for lead and mercury in binary system for bentonite, NCC and composite.

Table 2

Adsorption parameters for extended Langmuir model.

\begin{tabular}{|c|c|c|c|c|c|c|c|c|c|c|}
\hline \multirow[t]{2}{*}{ Adsorbent } & \multicolumn{2}{|c|}{ Initial concentration } & \multirow[t]{2}{*}{$\theta_{1}$} & \multirow[t]{2}{*}{$\theta_{2}$} & \multirow[t]{2}{*}{$q_{m, 1}(\mathrm{mmol} / \mathrm{g})$} & \multirow[t]{2}{*}{$q_{m, 2}(\mathrm{mmol} / \mathrm{g})$} & \multirow[t]{2}{*}{$K_{L, 1}(\mathrm{~L} / \mathrm{mmol})$} & \multirow[t]{2}{*}{$K_{L, 2}(\mathrm{~L} / \mathrm{mmol})$} & \multirow[t]{2}{*}{$Q_{1}(\mathrm{~kJ} / \mathrm{mol})$} & \multirow[t]{2}{*}{$\mathrm{Q}_{2}(\mathrm{~kJ} / \mathrm{mol})$} \\
\hline & $\mathrm{C}_{\mathrm{o}, \mathrm{Pb}}(\mathrm{mmol} / \mathrm{L})$ & $\mathrm{C}_{\mathrm{o}, \mathrm{Hg}}(\mathrm{mmol} / \mathrm{L})$ & & & & & & & & \\
\hline \multirow[t]{3}{*}{ Bentonite } & 0.48 & 0.50 & 0.66 & 0.34 & 0.16 & 0.05 & 5.21 & 3.61 & 8.31 & 20.00 \\
\hline & 0.97 & 0.50 & 0.67 & 0.33 & 0.17 & 0.05 & 5.23 & 3.60 & & \\
\hline & 1.45 & 0.50 & 0.67 & 0.33 & 0.17 & 0.05 & 5.26 & 3.59 & & \\
\hline \multirow[t]{3}{*}{ NCC } & 0.48 & 0.50 & 0.68 & 0.32 & 0.21 & 0.05 & 8.18 & 4.57 & -6.62 & -12.61 \\
\hline & 0.97 & 0.50 & 0.68 & 0.32 & 0.21 & 0.05 & 8.22 & 4.55 & & \\
\hline & 1.45 & 0.50 & 0.69 & 0.31 & 0.21 & 0.05 & 8.27 & 4.52 & & \\
\hline \multirow[t]{3}{*}{ Composite } & 0.48 & 0.50 & 0.70 & 0.30 & 0.28 & 0.06 & 10.87 & 4.99 & -4.74 & -6.46 \\
\hline & 0.97 & 0.50 & 0.70 & 0.30 & 0.28 & 0.06 & 10.91 & 4.96 & & \\
\hline & 1.45 & 0.50 & 0.70 & 0.30 & 0.28 & 0.06 & 10.97 & 4.92 & & \\
\hline
\end{tabular}

particular component towards the heat of adsorption. The original Langmuir equation assumes that there is no interaction between adsorbed molecules implying that the heat of adsorption is independent of coverage [27], and for real multicomponent system this assumption is not truly correct. By substituting Eqs. (8)-(11), the extended Langmuir model becomes 


$$
\begin{aligned}
& q_{e, 1}=q_{\mathrm{m}, 1} \theta_{1} \frac{K_{L, 1 \text { (single })} \times\left(\frac{Q_{1} \theta_{1}}{Q_{1} \theta_{1}+Q_{2}\left(1-\theta_{1}\right)}\right) C_{e, 1}}{1+K_{L, 1(\text { single })} \times\left(\frac{Q_{1} \theta_{1}}{Q_{1} \theta_{1}+Q_{2}\left(1-\theta_{1}\right)}\right) C_{e, 1}+K_{L, 2(\text { single })} \times\left(\frac{Q_{2}\left(1-\theta_{1}\right)}{Q_{1} \theta_{1}+Q_{2}\left(1-\theta_{1}\right)}\right) C_{e, 2}} \\
& q_{e, 2}=q_{\mathrm{m}, 2}\left(1-\theta_{1}\right) \frac{K_{L, 2(\text { single })} \times\left(\frac{Q_{2}\left(1-\theta_{1}\right)}{Q_{1} \theta_{1}+Q_{2}\left(1-\theta_{1}\right)}\right) C_{e, 2}}{1+K_{L, 1 \text { (single })} \times\left(\frac{Q_{1} \theta_{1}}{Q_{1} \theta_{1}+Q_{2}\left(1-\theta_{1}\right)}\right) C_{e, 1}+K_{L, 2(\text { single })} \times\left(\frac{Q_{2}\left(1-\theta_{1}\right)}{Q_{1} \theta_{1}+Q_{2}\left(1-\theta_{1}\right)}\right) C_{e, 2}}
\end{aligned}
$$

This fractional loading $(\theta)$ was originally developed by Langmuir which represents the fraction of the surface [28]. Now by assuming monolayer coverage of surface active sites, then in the binary system, the total of fractional loading must be equal to unity $\left(\theta_{1}+\theta_{2}=1\right)$ since the surface active sites will be occupied by either of $\mathrm{Pb}(\mathrm{II})$ or $\mathrm{Hg}$ (II) to form the monolayer surface coverage. The value of $Q$ can be obtained by the following equations:

$K_{L, 1 \text { (single) }}(T)=K_{L_{o}, 1} \exp \left(\frac{Q_{1}}{R T}\right)$

$K_{L, 2(\text { single })}(T)=K_{L_{o}, 2} \exp \left(\frac{Q_{2}}{R T}\right)$

where $R$ is the ideal gas constant $\left(0.008314 \mathrm{~kJ} \mathrm{~K}^{-1} \mathrm{~mol}^{-1}\right), T$ is the temperature $(K), K_{L}$ is the Langmuir affinity constant that can be determined from a single system $(\mathrm{L} / \mathrm{mmol})$. The value of $K_{L_{0}}$ and $Q$ are simply acquired through linear regression plotting of $K_{L \text { (single) }}$ versus $1 / T$ in which $K_{L_{0}}$ and $Q$ are obtained as intercept and slope, respectively [29].

To get a clear idea whether this proposed model is applicable, the experimental data $(0.48 \mathrm{mmol} / \mathrm{L} \mathrm{Pb}(\mathrm{II})+0.50 \mathrm{mmol} / \mathrm{L} \mathrm{Hg}(\mathrm{II}))$ were plotted against the original extended Langmuir and modified extended Langmuir and the results are presented in Fig. 9. It can be seen that the original extended Langmuir (Fig. 9a) can not fit the experimental data well. On the other hand, the modified extended Langmuir can fit the experimental data very well, confirming that the competition between adsorbates molecules occurred during the adsorption process. The binary adsorption of $\mathrm{Pb}$ (II) and $\mathrm{Hg}$ (II) onto bentonite, NCC and nanocomposite were fitted using Eqs. (12) and (13) and the results are presented in Fig. 10 and Table 2. It can be seen that at the same concentration of lead and mercury in the mixtures, the fractional loading of $\mathrm{Hg}(\mathrm{II})\left(\theta_{2}\right)$ is smaller than $\mathrm{Pb}(\mathrm{II})$, indicating that $\mathrm{Hg}$ (II) is less preferentially adsorbed on all adsorbents. These results have the same trend as the single component adsorption. Even the value of $\theta_{1}$ which refers to the fractional surface coverage of $\mathrm{Pb}$ (II) increases as the concentration of $\mathrm{Pb}$ (II) in the mixture increases for bentonite and NCC, but it remains unchanged for nanocomposite. This shows that composite attained maximum surface coverage for $\mathrm{Pb}$ (II) although the concentration of $\mathrm{Pb}$ (II) was three times higher than the initial concentration. The adsorption of $\mathrm{Pb}$ (II) and $\mathrm{Hg}$ (II) onto bentonite is exothermic, while both NCC and composite show endothermic adsorption. This correlates well with the adsorption in single system in which the adsorption capacity of NCC and composite increased with increasing temperature.

\section{Conclusion}

The feasibility of using NCC - bentonite nanocomposite as adsorbent for the removal of $\mathrm{Pb}$ (II) and $\mathrm{Hg}$ (II) was presented in this paper. The adsorption studies were conducted in single and binary systems. Langmuir isotherm gives better fit through all of the experimental data for the single system. The value of optimum $\mathrm{pH}$ for binary systems is not much different with the single system, which confirms that the adsorption mechanism in both of single and binary systems was similar. The adsorption capacity for lead is higher than mercury in both systems; this phenomenon indicated that functional group plays a major role in the adsorption mechanisms. The modified model could represent the binary experimental data very well.

\section{References}

[1] G. Crini, Recent developments in polysaccharide-based materials used as adsorbents in wastewater treatment, Prog. Polym. Sci. 30 (2005) 38-70.

[2] S.J. Einchorn, A. Dufresne, M. Aranguren, N.E. Marcovich, J.R. Capadona, S.J. Rowan, S. Weder, W. Thielemans, M. Roman, S. Renneckar, W. Gindl S. Veigel, J. Keckes, H. Yano, K. Abe, M. Nogi, A.N. Nakagaito, A. Mangalam, J. Simonsen, A.S. Benight, A. Bismarck, L.A. Berglund, T. Peijs, Review: current international research into cellulose nanofibers and nanocomposites, J. Mater. Sci. 45 (2010) 1-33.

[3] UNECE/FAO, Forest Products Annual Market Review 2014-2015, United Nation Publications, 2015.

[4] R. Batmaz, N. Mohammed, M. Zaman, G. Minhas, R.M. Berry, K.C. Tam, Cellulose nanocrystals as promising adsorbents for the removal of cationic dyes, Cellulose 21 (2014) 1655-1665.

[5] S. Ismadji, D.S. Tong, F.E. Soetaredjo, A. Ayucitra, W.H. Yu, C.H. Zhou, Bentonite hydrochar composite for removal of ammonium from Koi fish tank, Appl. Clay Sci. 119 (2016) 146-154.

[6] H.H. Murray, Applied Clay Mineralogy: Occurrences, Processing and Application of Kaolins, Bentonites, Palygorskite-Sepiolite, and Common Clays, first ed., Elsevier, Amsterdam, 2007.

[7] R. Srinivasan, Advances in application of natural clay and its composites in removal of biological, organic, and inorganic contaminants from drinking water, Adv. Mater. Sci. Eng., http://dx.doi.org/10.1155/2011/872531 (Article ID 872531).

[8] C.N. Wu, T. Saito, S. Fujisawa, H. Fukuzumi, A. Isogai, Ultrastrong and high gas barrier nanocellulose/clay-layered composites, Biomacromolecules 12 (2013) 1927-1932.

[9] H.G. Higgins, C.M. Stewart, K.J. Harrington, Infrared spectra of cellulose and related polysaccharides, J. Polym. Sci. 51 (1961) 59-84.

[10] P. Garside, P. Wyeth, Identification of cellulosic fibres by FTIR spectroscopy: thread and sigle fibre analysis by attenuated total reflectance, Stud. Conserv. 48 (2003) 269-275

[11] J. Lee, S.H. Kim, Y.J. Cho, Y.S. Nam, K.B. Lee, Y. Lee, Characterization and sequence determination of pen inks, read sealing inks, and laser toners by TOF-SIMS and ATR FTIR, Surf. Interface Anal. 46 (2014) 317-321.

[12] R.A. Merrill, E.G. Bartick, J.H. Taylor III, Forensic discrimination of photocopy and printer toners. I. The development of an infrared spectral library, Anal. Bioanal. Chem. 376 (2003) 1272-1278.

[13] F.E. Soetaredjo, A. Ayucitra, S. Ismadji, A.L. Maukar, KOH/bentonite catalysts for transesterification of palm oil to biodiesel, Appl. Clay Sci. 53 (2011) $341-346$.

[14] A. Kurniawan, H. Sutiono, N. Indraswati, S. Ismadji, Removal of basic dyes in binary system by adsorption using rarasaponin-bentonite: revisited of extended langmuir model, Chem. Eng. J. 189-190 (2012) 264-274.

[15] Y. Li, J. Zhan, L. Huang, H. Xu, H. Li, R. Zhang, S. Wu, Synthesis and photocatalytic activity of a bentonite/g- $\mathrm{C}_{3} \mathrm{~N}_{4}$ composite, RSC Adv. 4 (2014) $11831-11839$.

[16] L. Heath, W. Thielemans, Cellulose nanowhisker aerogels, Green Chem. 12 (2010) 1448-1453.

[17] Y. Peng, D.J. Gardner, Y. Han, A. Kiziltas, Z. Cai, M.A. Tshabalala, Influence of drying method on the material properties of nanocellulose I: thermostability and crystallinity, Cellulose 20 (2013) 2379-2392.

[18] Y. Sarikaya, M. Onal, B. Baran, T. Alemdaroglu, The effect of thermal treatment on some of the physicochemical properties of a bentonite, Clays Clays Miner. 48 (2000) 557-562. 
[19] H.C.H. Hahne, W. Kroontje, Significance of pH and chloride concentration on behavior of heavy metal pollutants: mercury(II), Cadmium(II), Zinc(II), and Lead(II), J. Environ. Qual. 2 (1973) 444-450.

[20] W.R. Knocke, L.H. Hemphill, Mercury(II) sorption by waste rubber, Water Res, 15 (1981) 275-282.

[21] L. Pauling, The Nature of the Chemical Bond, third ed., Cornell University, Ithaca, NY, 1960.

[22] A. Bondi, van der Waals volumes and radii, J. Phys. Chem. 68 (1964) 441-451.

[23] R.G. Pearson, Hard and soft acids and bases, J. Am. Chem. Soc. 85 (1963) 3533-3539.

[24] H.V. Olphen, Interlayer Forces in Bentonite, Publication No. 40, Exploration and Production Research Division, Shell Development Co., Houston, Texas, 1954.
[25] S.J. Allen, G. McKay, J.F. Porter, Adsorption isotherm models for basic dye adsorption by peat in single and binary component systems, J. Colloid Interface Sci. 280 (2004) 322-333.

[26] A. Kurniawan, H. Sutiono, N. Indraswati, S. Ismadji, Removal of basic dyes in binary system by adsorption using rarasaponin-bentonite: revisited of extended Langmuir model, Chem. Eng. J. 189-190 (2012) 264-274.

[27] D.M. Ruthven, Principles of Adsorption \& Adsorption Processes, Wiley-Interscience, United States of America, 1984.

[28] I. Langmuir, The adsorption of gases on plane surfaces of glass, mica and platinum, J. Am. Chem. Soc. 40 (9) (1918) 1361-1403.

[29] D.D. Do, Adsorption Analysis: Equilibria and Kinetics, Imperial College Press, London, 1998. 